\title{
Nuevo modelo de cooperativismo cubano: la importancia de las marcas colectivas para su desarrollo
}

\author{
Mabel Cándano Pérez \\ Profesora de Derecho de Propiedad Industrial y Derecho Mercantil, Directora del \\ Departamento de Derecho de la Universidad de Matanzas, Cuba.
}

Sumario: 1. Notas introductorias. 2. Las cooperativas no agropecuarias. Su tratamiento en la legislación cubana. 3. La marca colectiva y su relación con los Principios cooperativos que reflejan singularmente su esencia. 4. La marca colectiva como activo intangible de la cooperativa no agropecuaria. 5. Aspectos que impiden el desarrollo de la marca colectiva en las cooperativas no agropecuarias cubanas. 6. A modo de conclusiones. 7. Bibliografía.

Resumen: En Cuba, el régimen jurídico para las cooperativas no agropecuarias, aparece en el año 2012, se amplía de esta manera el cooperativismo a otros sectores de la economía. Cada vez es mayor el comercio con influencia externa y novedosa que se introduce, por lo cual se debe competir de forma leal en el comercio, actualizarse, renovarse y crecer, sin perder la identidad. El objeto de estudio de este trabajo es analizar la marca colectiva y las características comunes que tienen con estas asociaciones, teniendo en cuenta que el desconocimiento en su aplicación aplaza su explotación, que se vislumbra como una poderosa herramienta para la cooperativa no agropecuaria, a partir de las ventajas que ofrecen, por ser un bien intangible de mucho valor en las asociaciones de este tipo, que constituye el patrimonio esencial y la clave del éxito rotundo en el mercado.

Palabras claves: cooperativas no agropecuarias, marca colectiva, desarrollo local.

Abstrac: The juridic regimen in Cuban to non-agricultural cooperatives, to appear in the 2012, has been amplify like this the association to the others economic sectors and has been treat the join work of the people that in this moment has been confront the market of individual form. Every time to exit the trade with influence foreigner and new, for this has been to open de doors, to compete in the trade, to computing and increase without the identity. Has been to propose bring near the collective brands to the sector, to take into account that the ignorance, to postpone the working, that is the implement for the non-agricultural cooperatives.

Keyswords: non-agricultural cooperatives, collective brand, local development. 


\section{Notas introductorias}

En Cuba, a partir del año 2012 se establece el régimen jurídico para las cooperativas no agropecuarias ${ }^{1}$, ampliándose de esta manera el cooperativismo cubano a otros sectores de la economía y propiciando el trabajo conjunto de personas que hasta el momento enfrentaban el mercado de forma individual.

Esta medida tiene lugar en un contexto internacional propicio, coincidiendo con la proclamación por la Asamblea General de la Organización de las Naciones Unidas, del año 2012 como «Año Internacional de las Cooperativas» con el lema «Las cooperativas ayudan a construir un mundo mejor».

Todo ello tiene su historia previa en la Recomendación 193 de la Organización Internacional del Trabajo² ${ }^{2}$ incluida la Resolución 56/114 de las Naciones Unidas ${ }^{3}$, mediante la cual se insta a los gobiernos a alentar y facilitar la creación de cooperativas, y a tomar las medidas adecuadas para crear un entorno de apoyo para el desarrollo de las cooperativas.

La Alianza Cooperativa Internacional $(\mathrm{ACI})$, ha propuesto que el decenio 2011-2020 sea declarado una «Década Cooperativa». Con este fin, se presenta el proyecto «Desafío 2020», que establece que para el año 2020 el modelo cooperativo se debe consolidar a nivel planetario como: líder reconocido de la sostenibilidad económica, social y ambiental; el modelo preferido por la gente; el tipo de organización empresarial de más rápido crecimiento 4 .

1 Decreto-Ley 305 «De las Cooperativas no Agropecuarias», de fecha 11 de diciembre de 2012, regula un tipo de cooperativa diferente de las agropecuarias, aunque sea, como dice el propio legislador, con «carácter experimental», lo que implica su promulgación a título de prueba y con la intención previa de posteriores modificaciones e incluso de aplicaciones a otros ámbitos de la actividad económica.

El primer grupo aprobado de este tipo de cooperativas comenzó a funcionar el 1 de julio de 2013. Está compuesto por un total de 124 cooperativas, de las cuales 99 van a operar en mercados agropecuarios, 5 están relacionadas con el transporte de pasajeros; 6 con servicios auxiliares de transporte; 2 con reciclaje de desechos y 12 con actividades de construcción. Disponible en: www.granma.cu, en fecha 1 de julio de 2013.

2 Posteriormente, la Organización Internacional del Trabajo (OIT) publicó una actualización de las Directrices para la Legislación sobre Cooperativas, producidas por Hagen Henrÿ, Segunda edición actualizada de 2005. Disponible en:

http://www.ilo.org/empent/Publications/WCMS_094045/lang--en/index.htm.

3 Resolución aprobada por la Asamblea General el 19 de diciembre de 2001, Cooperatives in social development, A/ RES /56/114 que siguió al informe del Secretario General sobre Cooperativas en el desarrollo social distribuido en mayo de 2001.

4 MILLS, C. y DAVIES, W.: «Plan para una década cooperativa», Revista Alianza Cooperativa Internacional, núm. 1, año 13, p.2. 
El Año Internacional de las cooperativas ha sido un catalizador para este tipo de asociación y para aquellos que creen en la idea de la cooperación. El momento y la situación reclaman la adopción de nuevas medidas que permitan asegurar la durabilidad de las cooperativas, respaldar su actividad económica y consolidar su imagen en el mercado.

Para lograr esto, las cooperativas deben meditar sobre la manera en que se les percibe, tanto por quienes son miembros, como por quienes no integran la asociación. Con el presente trabajo se hace una breve valoración sobre la figura de la marca colectiva y las características comunes con este sector, si se tiene en cuenta que el desconocimiento en su aplicación, aplaza la explotación del referido signo distintivo que se aprecia como una poderosa herramienta para la cooperativa no agropecuaria. A su vez se analizan las ventajas que éstas le ofrecen, así como el hecho de ser un bien intangible de mucho valor en las asociaciones de este tipo, lo cual constituye el patrimonio esencial y la clave del éxito rotundo en el mercado.

Para ello, es importante distinguir entre identidad y mensaje. En sentido general, la identidad es el significado que tienen las cooperativas para el propio sector y sus miembros: economía social, responsabilidad social cooperativa, desarrollo local, participación democrática, sostenibilidad, empoderamiento social, innovación social, valores y principios cooperativos 5 .

El mensaje es la forma en que se comunica y se proyecta la identidad de las cooperativas hacia el mundo externo mediante la educación, el suministro de información, el marketing, los logotipos y otras formas de relación con quienes no son cooperativistas.

Por tanto, el mensaje tiene que gestionarse correctamente para contribuir a largo plazo a los intereses de las cooperativas. La palabra que se utiliza con mayor frecuencia para referirse al mensaje es «marca», y se utiliza dentro del sector cooperativo, haciéndose referencia a la consolidación de la «marca» cooperativa.

En este sentido la marca colectiva es un signo distintivo que se aviene perfectamente a los requerimientos de los asociados ${ }^{6}$. Definida

5 Fernández Novoa, C.: La Marca Comunitaria, Montecorvo, Madrid, España, 1990, p.65. Consultado en diciembre de 2013. Disponible en: books.google.com.cu/books.

6 Decreto-Ley 203/99 «De marcas y otros signos distintivos», edición extraordinaria No.3 del 2 de mayo de 2000, título IV, artículo 90. 1: "Pueden registrar marcas colectivas las agrupaciones, debidamente constituidas, de personas con un interés económico en común, con el fin de distinguir los productos o servicios de las personas asociadas, de los productos o servicios de otras personas. A estos efectos, dichas agrupaciones deben estar integradas por fabricantes, productores, prestadores de servicios o comerciantes que tengan capacidad, con arreglo a la ley, para ser sujetos de derechos y obligaciones, en especial, por las personas jurídicas estatales o privadas». 
como un signo que distingue la procedencia geográfica, el material, el modo de fabricación, los conocimientos y experiencias de los miembros de la asociación, la calidad u otras características de los productos o servicios de una colectividad?

La marca colectiva propicia la creación de estrategias comunes, genera publicidad a regiones o localidades potenciando sus elementos identitarios y refuerza el carácter cooperativo-colectivo de la agrupación, así como es un instrumento al servicio de la Economía social que nace de la propia comunidad, comprometida con el desarrollo local. Sin embargo su esencia trae aparejada la renovación continua de la asociación que identifica, la búsqueda de nuevas alternativas que atraigan nuevos clientes, la transformación del medio que rodea la cooperativa haciéndolo más atractivo.

\section{Las cooperativas no agropecuarias. Su tratamiento en la legislación cubana}

Para regular todo lo relacionado con esta forma de producción, el estado cubano promulga el Decreto Ley No. 305 «De las Cooperativas no Agropecuarias» y el Decreto No. 309 «Reglamento de las Cooperativas no Agropecuarias de Primer Grado» ${ }^{8}$. Es así que a partir de abril de 2013 se aprueba la constitución de un grupo de cooperativas no agropecuarias de manera experimental ${ }^{9}$.

En aras de un mejor entendimiento de este tipo de cooperativas y su posible relación con las marcas colectivas, se hace necesario desarrollar un breve acercamiento a la legislación que las regula, específicamente al Decreto Ley No. 305 «De las Cooperativas no Agropecuarias».

7 Bercovitz, A.: Nociones introductorias sobre las marcas, España, 1989. Consultado en diciembre de 2013. Disponible en: books.google.com.cu/books.

8 Ambos cuerpos legales fueron publicados en la Gaceta Oficial Extraordinaria No. 53, del 11 de diciembre de 2012, disponible en: http//www.gacetaoficial.cu

9 «(...) fueron 126, a las cuales se unieron 71 en el mes de julio y 73 en octubre, de la cifra total ya se han constituido 224 . (...)las nuevas 228 cooperativas (...) se reiteran en los sectores de comercio, gastronomía y servicios (186), construcción (12), transporte (3), industria (15) y alimentación (1), al tiempo que se incorporan en materia de energía (5) y servicios contables (6).» Tomado de: Periódico Granma. Edición única No. 52, de fecha, 3 de marzo de 2014. 
Atendiendo a su conceptualización según lo establece el artículo 21:

«La cooperativa es una organización con fines económicos y sociales, que se constituye voluntariamente sobre la base del aporte de bienes y derechos y se sustenta en el trabajo de sus socios, cuyo objetivo general es la producción de bienes y la prestación de servicios mediante la gestión colectiva, para la satisfacción del interés social y el de los socios.»

Sobre la base de lo expresado en este artículo, sólo resta subrayar, la existencia de total convergencia entre los elementos que conforman el concepto de cooperativa y aquellos que pudieran derivarse de los aspectos constitutivos, finalidad y alcance de una marca colectiva, que establece como definición:

«signo que sirve para distinguir las singularidades, el origen geográfico o cualquier otra característica común de productos o servicios de una colectividad $\gg{ }^{10}$, debiéndose tal homogeneización al cumplimiento de las normas de su reglamento de uso.

Son comunes al concepto de marca colectiva, ya sea explícita o implícitamente, un grupo de elementos esenciales que se analizarán por ser determinantes a la hora de comprender esta figura y su posible utilización por las cooperativas no agropecuarias creadas en Cuba. Siguiendo esta línea de pensamiento dichos elementos esenciales serán analizados teniendo en cuenta su expresión en el Decreto Ley 203 de Marcas y otros signos distintivos, ya antes mencionado, vigente para nuestro país.

Se pudiera mencionar como elementos afines de ambas figuras, los que se mencionan a continuación:

- Perfecta armonía entre la finalidad económica y social que persiguen tanto la cooperativa como la marca colectiva, lo cual se canaliza de manera coherente en dar respuesta a intereses y demandas de la economía y la sociedad con una fuerte expresión en lo local, como base para el desarrollo.

- Indispensable que tanto la cooperativa como la marca colectiva nazcan de un proceso orgánico y voluntario, preferentemente no inducido. De lo que se deriva que la unión no forzada, sólo puede dar lugar en ambos casos, a una gestión democráticamente colectiva, pero controlada - por mecanismos establecidos en estatutos y reglamentos de uso- por sus miembros o usua-

10 Rodríguez Calvo, H.: Las marcas colectivas en Cuba. Tesis para optar por el Título de Máster en Gestión de la Propiedad Intelectual, La Habana, Cuba, 2013, p. 69. 
rios según proceda, siempre en la búsqueda del cumplimiento de objetivos comunes para los asociados.

Este tipo de cooperativa opera muy parecido a las Cooperativas de Producción Agropecuarias ${ }^{11}$ creadas en el país a partir de 1975 y que se considera, tampoco pueden usar la marca colectiva para posicionar sus productos en el mercado, ya que se integran por personas naturales que decidan voluntariamente asociarse entre sí, solo con la finalidad de adquirir conjuntamente insumos y servicios, comercializar productos y servicios, o emprender otras actividades económicas, conservando los socios la propiedad sobre sus bienes. Este literal nos describe un supuesto diferente, pues se habla de la asociación voluntaria de personas naturales que se integran con determinados fines, pero preservando los socios la propiedad sobre sus medios de producción.

Se puede hablar potencialmente de una asociación que bien pudiera ser titular de una marca colectiva, al tiempo que existe una pluralidad de usuarios prestos a ser autorizados para usar el signo distintivo. De tal forma la marca colectiva servirá para distinguir en el mercado los productos y/o servicios de los miembros de la asociación cooperativa. Válido es destacar que salvando lógicas diferencias, este tipo de cooperativa no agropecuaria tiene varios puntos de convergencia con las Cooperativas de Créditos y Servicios ${ }^{12}$ que surgen en el país a partir del año 1960 y que si pueden ser titulares de marcas colectivas, pero solo haremos mención a las cooperativas no agropecuarias.

\section{La marca colectiva y su relación con los Principios cooperativos que reflejan singularmente su esencia}

Los principios y valores son los elementos distintivos de las organizaciones y empresas cooperativas. Ya en 1844, los Pioneros de Rochdale, fundadores de la primera cooperativa de la historia, habían for-

11 Ley No.95, "Ley de Cooperativas de Producción Agropecuaria y de Créditos y Servicios», Gaceta Oficial de la República de Cuba No.72, con fecha 29 de noviembre de 2002, establece en su artículo 4: La Cooperativa de Producción Agropecuaria es una entidad económica (...) con patrimonio y personalidad jurídica propios, constituida con la tierra y los bienes aportados por los agricultores pequeños (...)

12 Ley No.95, "Ley de Cooperativas de Producción Agropecuaria y de Créditos y Servicios» artículo 5: La Cooperativa de Créditos y Servicios es la asociación voluntaria de los agricultores pequeños que tiene la propiedad o el usufructo de sus respectivas tierras y demás medios de producción, así como sobre la producción que obtienen (...). Tiene personalidad jurídica propia y responde de sus actos con su patrimonio. 
mulado un sistema de principios simple, claro y contundente, que les aseguró la conducción de la organización en beneficio de sus miem$\operatorname{bros}^{13}$.

La nueva Declaración de Identidad Cooperativa adoptada por la II Asamblea General de la $\mathrm{ACl}$ — que se realizara en el mes de setiembre de 1995 en la ciudad de Manchester, en oportunidad de la celebración del Centenario de la Alianza - incluye una nueva definición de cooperativa y una revisión de la formulación de los Principios y Valores Cooperativos. La nueva formulación mantiene la esencia de un sistema de principios y valores que demostró ser eficiente en casi 170 años de historia y contribuyó a transformar al cooperativismo en una de las mayores fuerzas sociales y económicas a nivel mundial, a la vez que incorpora nuevos elementos para una mejor interpretación del momento histórico actual.

Una cooperativa es una asociación autónoma de personas que se han unido voluntariamente para hacer frente a sus necesidades y aspiraciones económicas, sociales y culturales comunes por medio de una empresa de propiedad conjunta y democráticamente controlada.

Se basan en los valores de ayuda mutua, responsabilidad, democracia, igualdad, equidad y solidaridad. Siguiendo la tradición de sus fundadores sus miembros creen en los valores éticos de honestidad, transparencia, responsabilidad social y preocupación por los demás.

Dentro de los principios cooperativos, se hace mención a:

- Membresía abierta y voluntaria

Las cooperativas son organizaciones voluntarias abiertas para todas aquellas personas dispuestas a utilizar sus servicios y dispuestas a aceptar las responsabilidades que conlleva la membresía sin discriminación de género, raza, clase social, posición política o religiosa.

- Control democrático de los miembros

Las cooperativas son organizaciones democráticas controladas por sus miembros quienes participan activamente en la definición de las políticas y en la toma de decisiones.

Los hombres y mujeres elegidos para representar a su cooperativa, responden ante los miembros.

En las cooperativas de base los miembros tienen igual derecho de voto (un miembro, un voto), mientras en las cooperativas de

13 Vid. Romero Calero, J.: La marca colectiva en la gestión empresarial cubana, Tesis para optar por el grado científico de Máster en Gestión de la Propiedad Intelectual, La Habana, Cuba, 2009, p. 38. Consultado en fecha: 27 de abril de 2015. 
otros niveles también se organizan con procedimientos democráticos.

- Participación económica de los miembros Los miembros contribuyen de manera equitativa y controlan de manera democrática el capital de la cooperativa. Por lo menos una parte de ese capital es propiedad común de la cooperativa.

Usualmente reciben una compensación limitada, si es que la hay, sobre el capital suscrito como condición de membresía.

Los miembros asignan excedentes para cualquiera de los siguientes propósitos: El desarrollo de la cooperativa mediante la posible creación de reservas, de la cual al menos una parte debe ser indivisible; los beneficios para los miembros en proporción con sus transacciones con la cooperativa; y el apoyo a otras actividades según lo apruebe la membresía.

- Autonomía e independencia

Las cooperativas son organizaciones autónomas de ayuda mutua, controladas por sus miembros.

Si entran en acuerdos con otras organizaciones (incluyendo gobiernos) o tienen capital de fuentes externas, lo realizan en términos que aseguren el control democrático por parte de sus miembros y mantengan la autonomía de la cooperativa.

- Educación, formación e información

Las cooperativas brindan educación y entrenamiento a sus miembros, a sus dirigentes electos, gerentes y empleados, de tal forma que contribuyan eficazmente al desarrollo de sus cooperativas.

Las cooperativas informan al público en general, particularmente a jóvenes y creadores de opinión, acerca de la naturaleza y beneficios del cooperativismo.

- Cooperación entre cooperativas

Las cooperativas sirven a sus miembros más eficazmente y fortalecen el movimiento cooperativo trabajando de manera conjunta por medio de estructuras locales, nacionales, regionales e internacionales.

- Compromiso con la comunidad

La cooperativa trabaja para el desarrollo sostenible de su comunidad por medio de políticas aceptadas por sus miembros.

Ahora bien, se debe establecer los elementos que demuestren la pertinencia del uso de la marca colectiva por parte de las cooperativas. A estos efectos es importante analizar los principios cardinales que sus- 
tentan el ejercicio de esta colectividad, pues la esencia misma del signo distintivo se ve reflejada en algunos de ellos.

«Los principios cooperativos son los parámetros en virtud de los cuales funciona la actividad diaria de la asociación. Sin embargo no constituyen simplemente mandamientos en base a los cuales operan los socios, sino más bien estructuras habilitadoras, agentes vigorizantes por medio de los cuales las cooperativas pueden asir el futuro» ${ }^{14}$.

Los principios cooperativos que se analizan a continuación reflejan singularmente la esencia misma de la marca colectiva, a saber: el Control democrático de los miembros y el Compromiso con la comunidad.

El primero hace referencia al espíritu de democracia que debe existir en cada cooperativa y reafirma el derecho de los miembros de involucrarse efectivamente en la determinación de políticas y en la toma de decisiones.

Entre las particularidades de la marca colectiva que la hacen coincidir con este principio, se encuentra la de desarrollar estrategias comunes que permitan la colaboración entre los socios, a fin de estandarizar la calidad de los productos y mantener con ello el valor del signo distintivo.

El reglamento de uso de la marca colectiva ${ }^{15}$, es otro pilar en el que se ponen de manifiesto estas características; en tal sentido se observa la posibilidad que tienen los socios de decidir democráticamente la forma en que se usará la marca, donde los beneficios económicos por su explotación corresponden en principio a todos por igual. La existencia de un reglamento de uso común propicia la actuación coherente, uniforme, la especialización, eficiencia y fortalecimiento organizacional de la agrupación titular del signo ${ }^{16}$.

14 Divar Garteizaurrecoa, J.: «El Derecho comparado cooperativo en Europa», Anuario de estudios cooperativos, 1988, pp. 111 y ss.

15 «Cada reglamento de uso es la norma particular de la concreta norma; rige las relaciones internas entre el titular de la marca y los usuarios de la misma y de éstos entre sí. Una conducta contraria al reglamento tendrá las consecuencias previstas en el mismo (...)». CALDERÓN, K.: La marca colectiva, un beneficio para las Micro, Pequeñas y Medianas Empresas de Guatemala. Disponible en: http://www.sieca.org. gt/publico/ProyectosDeCooperacion/Proalca/PI/Revistas/ R2A8/LA\%20MARCA\%20COLECTIVA.htm.

16 El Decreto Ley 203 de Marcas y otros signos distintivos. Publicado en la Gaceta Oficial de la República de Cuba, edición extraordinaria No.3 del 2 de mayo de 2000 establece al respecto en su Artículo 91.1: La solicitud de registro de una marca colectiva debe incluir un reglamento de uso de dicha marca, el que indique los datos de identificación de la asociación, las personas autorizadas para utilizar la marca, las condiciones de afiliación a la asociación, las condiciones de uso de la marca y los motivos por los que puede prohibirse el uso de la marca a un integrante de la asociación. 
La creación de una marca colectiva debe acompañarse del desarrollo de ciertas normas, criterios y estrategias comunes. Requiere necesariamente, poner en marcha procesos asociativos que impliquen el compromiso de homogeneizar el servicio o estandarizar la calidad del producto para lograr su presencia en el mercado y mantener el valor de la marca. ${ }^{17}$

Asimismo el propio sistema colectivo para la gestión de la marca que se establece reglamentariamente permitirá el flujo e intercambio de parámetros, soluciones e incluso identificación de problemas comunes, facilitándose así el aumento de la eficiencia. Su empleo también refuerza la difusión efectiva y publicitaria del signo al propiciarse un uso por varias personas y enfocar el patrimonio de todos en desarrollar una marca común ${ }^{18}$.

El principio cooperativo de Compromiso con la comunidad, no deja de reconocer que las cooperativas son organizaciones que existen en primera instancia para el beneficio de sus miembros. Precisamente por esta fuerte asociación con sus miembros, casi siempre en un espacio geográfico específico, la mayor parte del tiempo las cooperativas están íntimamente ligadas a sus comunidades ${ }^{19}$.

Tienen la responsabilidad especial de asegurar la continuidad del desarrollo de su comunidad en los aspectos económico, social, cultural y medioambiental. Este principio deja entonces en mano de los miembros, decidir qué tanto y en qué forma una cooperativa debe contribuir con su comunidad.

Esta responsabilidad social de la cooperativa que a su vez coincide con la de la marca colectiva, tiene su fundamento en que la sociedad cooperativa por su propia definición y concepción empresarial, constituye un claro ejemplo de empresa donde los principios y valores que la definen avalan la actitud responsable.

Para las cooperativas «no se trata sólo de hacer economía eficaz con una mayor dosis de sensibilidad social, sino que es, en su esencia, pensar y hacer economía de otra manera. Consiste en mostrar que es

17 Chevalier, M.: Prólogo por qué las marcas son buenas para usted, Michel Chevalier, Gerald Mazzalovo, Belacqva Barcelona, 2005, p. 37.

18 García Muñoz-Najar, LA.: Marcas Colectivas, Marcas de Certificación y denominaciones de origen. Acerca de las normas de calidad y uso de los signos distintivos para competir en el mercado, INDECOPI, Perú, 2012, p. 42.

19 Paz Canalejo, N.: «La Asamblea General en la Ley 27/1999 de Cooperativas: reflexiones críticas», REVESCO, núm 78, 2002, pp. 121 y ss. 
posible ser competitivos poniendo a la persona y al colectivo en un primer plano» 20 .

Algunas señales de fortaleza del cooperativismo son:

- El cooperativismo da respuesta a nuevas necesidades sociales para la inclusión e inserción social y laboral de personas cuya empleabilidad resulta difícil.

- Provee de servicios de interés general para sectores, usuarios, que de otra forma no tendrían acceso a los mismos.

- Moviliza recursos locales de todo tipo (económicos, productivos, intelectuales, de liderazgo).

- Contribuye con los planes y programas nacionales de desarrollo económico y social.

«Desde sus inicios, las cooperativas han tenido en cuenta que sus acciones benefician a la gran mayoría de sus socios, incluidos los trabajadores, la comunidad y el entorno en el que operan ${ }^{21}$.

Por otra parte no debe perderse de vista, que el trabajo privado individual no sustenta ninguna economía nacional, ni es capaz de cubrir carencias y solventar las necesidades de la sociedad. Por su arraigo en importantes colectivos sociales y su reconocimiento jurídico internacional, la cooperativa es, más que ningún otro tipo de empresa, quien mejor representa a la economía social22.

Como colofón de este tipo de asociación y como ejemplo de signo distintivo destinado también a los actores de la economía social se encuentra la marca colectiva. ${ }^{23}$

Sin embargo, esta figura marcaria al representar los actores de la economía social se vincula a un concepto que ha evolucionado en los últimos años y que se manifiesta como parte integrante del referido signo distintivo.

20 GonzÁlez GutiérRez, A.: «Economía y sociedad: los retos del modelo económico», Cuba: Investigación Económica, julio-diciembre, 2007, núm 3-4, pp.1-55.

21 OFICINA CUBANA DE LA PROPIEDAD INDUSTRIAL:: Manual de Marcas para el Empresariado Cubano/ OCPI, Departamento de Marcas, La Habana, 2014.

22 La relación RS y Economía Social se fundamenta claramente en la Carta de Principios elaborada por la Conferencia Europea Permanente de Cooperativas, Mutualidades, Asociaciones y Fundaciones (CEF-CMAF), hoy en día y desde 2008 denominada como Social Economy Europe y que constituye el referente para la coordinación a nivel comunitario de todas aquellas iniciativas que tengan que ver con la Economía Social». Oficina Cubana de la Propiedad Industrial. Manual... ob. cit. p. 6.

23 Fernández Novoa, C.: Tratado Sobre Derecho de Marcas, Marcial Pons, Ediciones Jurídicas y Sociales, S.A, Madrid, 2001, p. 554. 
Es destacable la dimensión cooperativa de este proceso, el cual exige la colaboración de múltiples organismos y la creación de emprendimientos de la economía social en forma de cooperativas, asociaciones, entre otros.

La marca colectiva asume su responsabilidad en la economía social y frente al desarrollo local, precisamente cuando se convierte en portavoz de las potencialidades endógenas del territorio donde los productos o servicios son elaborados u ofertados, o donde radica la agrupación titular del signo 24 .

Al plasmar estas particularidades, no solo mejora el reconocimiento de los productos dentro del país, sino que también proporciona un marco para la comercialización de los mismos en el exterior, de ahí la necesidad de una mutua cooperación entre los productores locales.

Otro de los objetivos de esta herramienta, consiste en fortalecer la producción y la comercialización de los emprendimientos económicos otorgándoles valor agregado y mayor visibilidad, además de garantizar su calidad. De igual forma, promueve el compromiso social, fomentando el comercio justo y el consumo responsable.

Las cooperativas no agropecuarias por su mayor organización, niveles de producción y vinculación con un público más amplio son la cara visible de la localidad cubana ${ }^{25}$. Por lo tanto, uno de los medios que tienen para proyectar su esencia y fortalecer su imagen en el mercado es el uso de este signo distintivo.

Tampoco debe dejarse de lado las características particulares de cada uno de los integrantes de la cooperativa que, en la medida que no se opongan al proyecto colectivo, también serán parte importante del valor de la marca. Por lo tanto, la vinculación con la comunidad es inherente a la marca colectiva, ya que la misma al proyectar la imagen de un grupo de personas, sus valores, el sentido social de trabajo; está reflejando en esa pequeña muestra, a toda una ciudad o un municipio determinado.

En la medida que la cooperativa asuma mayor responsabilidad y compromiso social, y la marca colectiva distinga productos y servicios de calidad, su entrega será retribuida por el público. De esta manera, los propios vecinos de la zona se constituirán en sus principales promotores. «(...) será una publicidad sobre la base de sentimientos de orgu-

24 Idem

25 Al cierre de 2014, Cuba contaba con 345 cooperativas no agropecuarias, la mitad de ellas en La Habana, de acuerdo con un informe de la Oficina Nacional de Estadística e Información (ONEI), que reporta un total de 10.024 entidades económicas en todo el país, la menor cifra de los últimos cinco años. 
Ilo sobre lo autóctono, lo nacional; alejada de la publicidad convencional y mediática por fluir de manera natural (...)»26

Según la doctrina de SÁNCHEZ CALERO27 es considerable el efecto psicológico que el éxito de una marca colectiva puede generar en la comunidad y en las demás empresas. Sentimientos de orgullo hacia el territorio donde se desarrollan los productos y servicios a los que contribuyen directa o indirectamente los habitantes de la zona.

El desarrollo de la marca encauzará el fortalecimiento organizacional de la cooperativa, por ser un factor de acción común y de cohesión social que, al mismo tiempo, es determinante para el empoderamiento y la sostenibilidad de este emprendimiento. Mejorará la producción y permitirá el posicionamiento comercial de los productos en diversos espacios - ecoferias, atención a hoteles y restaurantes, entre otros-con mayor visibilidad, garantizando su calidad bajo los criterios establecidos en el reglamento de uso.

Existen actividades productivas donde al Estado contrata a cooperativas no agropecuarias por la agilidad de las prestaciones, es decir, por la cantidad de productos que pueden entregar en un tiempo reducido; por la calidad de los servicios también, debido a la especialización de varias personas en una determinada esfera productiva.

Sin duda alguna este signo distintivo tiene una gran fuerza comercial, pues su identidad se sustenta en valores culturales, conocimientos tradicionales, cualidades y habilidades comunes de los empresarios.

En Cuba existen valores naturales y humanos que pueden preservarse, incrementarse y trasmitirse con el uso de estas marcas a favor de la economía y la identidad nacional28.

Esta lógica corresponde a que se beneficia al poner en el mercado y proteger productos característicos tradicionales de una región, fundamentalmente por el reconocimiento y personalidad que desarrolla esa localidad y que en ocasiones se refleja rápidamente al exterior.

Por consiguiente se estimula la oferta de bienes y servicios y se diversifican renglones que en mayor o menor escala tienen la posibilidad de complementar la producción nacional. Se agrega valor al producto, pues se percibe como de una calidad regulada y original, asegurándose de esta forma una clientela fija.

26 Romero Calero, J.: La marca..., ob. cit., p. 54.

27 Sánchez Calero, J.: Instituciones de Derecho Mercantil, Editoriales de Derecho Reunidas, España, 1994, p. 359.

28 Rodríguez Calvo, H.: "Las marcas: clave estratégica para las PYMES en América Latina», Rendija: Revista Cubana de la Propiedad Industrial, núm 5, junio 2005, pp. 41-56. 
La marca colectiva promueve una mejor interacción económica entre el campo y la ciudad y es una herramienta para involucrar en un trabajo conjunto a diversas instituciones en favor del desarrollo local.

En resumen, pueden apuntarse como ventajas de la marca colectiva las siguientes:

- La marca es explotada por un conjunto de personas, por lo tanto, se reducen los costos de colocar productos o servicios en el mercado de forma individual.

- Permite a un grupo de cuentapropistas enfrentar el mercado en forma conjunta, obligándose a contar con una estrategia común.

- El uso de marcas colectivas no impide utilizar marcas individuales o propias.

- Permite entregar información al turista.

- Da a conocer la forma usual de fabricación de los productos.

- Aprovechar las expectativas que tienen los consumidores de los productos provenientes de determinadas zonas geográficas.

- Se constituye en una herramienta para impulsar la publicidad de regiones o localidades potenciando sus elementos identitarios (desarrollo de marcas locales).

- Aumentar el valor de comercialización de los bienes y servicios generados por actores de la economía social.

- Ayuda a combatir la falsificación de los productos y la competencia desleal de terceros que intenten aprovecharse de la fama adquirida identificando sus productos o servicios con un signo que goza de prestigio en el comercio, sin cumplir con los requisitos reglamentarios.

- Garantiza a los consumidores un nivel de calidad en los productos o servicios que la llevan, que en muchos casos es superior a los estándares exigidos por las normas técnicas y sanitarias;

- Fomentar la creación y durabilidad de las cooperativas no agropecuarias $^{29}$.

La marca colectiva más allá de generar solvencia económica a la cooperativa y a cada uno de sus socios, tiene que verse como impulsora del progreso local. Es un hecho que esta figura marcaria apoyada en su agrupación, resulta fuente generadora de empleo y financiación de proyectos comunitarios. Su radio de acción, por tal motivo, puede

29 Según datos de la ONEI, se habían creado 240 cooperativas no agropecuarias, hasta el mes de octubre de 2014. 
traspasar fronteras inmediatas y colocarse a nivel nacional como base sólida que asimile y promueva los cambios socio-económicos que surgen en $\mathrm{Cuba}^{30}$.

\section{La marca colectiva como activo intangible de la cooperativa no agropecuaria}

Las marcas tienen un valor económico y un valor jurídico. El valor jurídico es el mismo para todas las marcas registradas, es ilimitado en el tiempo en tanto vayan siendo renovadas. El valor económico está muy vinculado al hecho de ser consideradas activos intangibles ${ }^{31}$.

Los activos son un recurso o un bien económico propiedad de una empresa, con el cual se obtienen beneficios. Los activos de las empresas varían de acuerdo con la naturaleza de la actividad desarrollada y según su materialidad pueden clasificarse en tangibles o intangibles ${ }^{32}$.

Los activos intangibles son aquellos recursos obtenidos por una empresa que no son bienes físicos. Estos otorgan un derecho o privilegio inyectándole valor agregado a la misma. Los activos intangibles comprenden los Derechos de autor, las patentes, el know how y las marcas registradas. Hoy en día son más importantes que los llamados activos tangibles.

La marca en el tráfico económico se convierte en mercancía, de lo cual se deduce que es susceptible de valoración económica y forma parte del capital contable de la empresa. Por su inmaterialidad, al ser una propiedad incorpórea, resulta bien difícil la cuantificación de su valor. Lo cierto es que, para muchas empresas, el sistema de marcas constituye su patrimonio esencial y la clave del éxito rotundo en el mercado.

Evidentemente la marca colectiva cubana se enfrenta hoy a grandes retos ${ }^{33}$. Por una parte debe asumirse como activo intangible de la cooperativa no agropecuaria, o sea, generadora de capital económico

30 Candano Perez, M.: «El Derecho marcario y la influencia de la marca colectiva en el turismo cubano», Retos turísticos, 2012, ISSN: 1681- 9713, p. 43.

31 Fernández NovoA, C.: Tratado sobre Derecho de Marcas, Ediciones Jurídicas y sociales Madrid, 2001.

32 González Gutiérrez, A.: «Economía y sociedad: los retos del modelo económico», Cuba: Investigación Económica, núm 3-4, julio-diciembre 1997, pp.1-55.

33 En Cuba, no se ha registrado hasta la fecha ninguna marca colectiva, según datos ofrecidos por la Oficina Cubana de la Propiedad Industrial. Consulte el sitio: www. ocpi.cu. 
a partir del valor agregado que inyecte. Pero por otro lado tiene que fundamentar ese valor agregado en productos y servicios de calidad.

Debe buscarse la oferta de productos con identidad. En muchos casos, el precio no es el factor fundamental de la decisión de compra, sino aspectos como la satisfacción de placer y la atracción por lo bello, lo agradable, lo nutritivo, lo natural y lo exótico, entre otros.

Para ello, es necesario incorporar en la propia oferta, instrumentos que faciliten la percepción de la diferenciación por parte de los consumidores. En este caso el instrumento idóneo será la marca colectiva.

En general son vistas como más confiables, menos propensas a desarrollar comportamientos oportunistas y aprovecharse del consumidor precisamente por ser reconocidas internacionalmente como instituciones de la economía social con una elevada responsabilidad hacia la comunidad 34 .

Las cooperativas deben valorar al consumidor para mantenerse y superarse en el tiempo, para ello las siguientes consignas son una parte fundamental del cooperativismo:

- El concepto de Valor Consumidor es un compromiso que las cooperativas deben asumir. El valor del consumidor es tener un compromiso en la defensa de los consumidores, a través de la oferta de productos sanos, saludables y seguros, respetando el medio ambiente. En el caso de las cooperativas que brindan servicios se debe tener en cuenta que los mismos sean útiles, provechosos, que sean claros y sencillos de comprender. Además se debe tener una política de comunicación transparente que incentive la retro alimentación como parte del proyecto cooperativo.

- Las cooperativas deben medir la relación entre los trabajadores y los consumidores.

- Medir, controlar y buscar la mejora continua de la percepción del consumidor con respecto a la cooperativa, sus productos y/o servicios.

- Destinar un porcentaje anual a la mejora y mantenimiento de la imagen institucional de la cooperativa.

- Sumar a algunas de sus actividades tanto a los trabajadores como a los socios y los consumidores.

34 VARgas VASSEROt, C.: La actividad cooperativizada y las relaciones de la cooperativa con sus socios y con terceros. Navarra: Aranzadi, 2006, pp. 248 y ss. 
- Tener un sector dentro de la cooperativa que se dedique al consumidor. ${ }^{35}$

La aparición de la noción de consumidor está directamente vinculada con el desarrollo de la sociedad y el avance de nuevas tecnologías que permiten la producción masiva de elementos de todo tipo.

La competencia continua hace que las empresas, y en este caso las cooperativas - que son también empresas tanto en su sentido económico como jurídico en cuanto realizan actividades económicas y sociales en forma organizada, combinando capital y trabajo y procurando medios y resultados de eficiencia, eficacia y economía - busquen captar y fidelizar a sus consumidores. ${ }^{36}$ Esto implica que el producto y/o servicio que se acerque mejor a las preferencias de un individuo determinado, estará en una mejor posición a la hora de convertir a este individuo en un cliente.

Es un hecho constatable que los consumidores son cada día más conscientes, exigentes, incluso más comprometidos y responsables en su condición de tales y por ello, las cooperativas deberían orientar sus productos y/o servicios con un desarrollo de los mismos ajustados a las expectativas del consumidor de forma continua, intensificándolos valores cooperativos y sus ventajas competitivas como motivación y factor de atracción de aquel.

Hay múltiples factores para que un consumidor elija un producto y/o servicio, pero las cooperativas, por su fin y razón de permanencia, pueden acercarse a los diversos segmentos de mercado, particularmente a través de la marca colectiva.

Ciertamente la función esencial de este signo distintivo no es la de una marca de garantía, o sea, certificar la calidad de los productos y servicios a los que se aplica, aun cuando esta no fuera su función primordial, sí había todo un andamiaje detrás de la marca colectiva que permitía informar al cliente sobre la trazabilidad del producto: su forma de elaboración, materiales utilizados y técnicas llevadas a cabo.

En la práctica, existe un componente de confianza en muchos bienes y servicios precisamente por estar identificados con determinada marca, de hecho los productos pueden ser sustituidos por otros que mientras la marca sea la misma, ese componente de confianza permanecerá intacto.

35 LeON LUNA, D.: La marca colectiva en el sector cooperativo, Tesis en opción al grado de licenciado en Derecho, Universidad de Matanzas, 2015.

${ }^{6}$ Girón TenA, J.: Derecho de sociedades. En: AA.VV. Tomo I: parte general, Sociedades Colectivas y Comanditarias, Editorial G.T, Madrid, 1976. 
En el caso de la marca colectiva esta situación adquiere especial significado, ya que asegura un alto nivel de confianza basado en principios, valores, conocimientos tradicionales, requisitos académicos, mejores estándares, homogeneidad en el servicio, origen empresarial y la inevitable responsabilidad social que genera la misma.

El cooperativismo es capaz incluso, de crear oportunidades de trabajo en territorios que no son atractivos para el inversor tradicional. Pero si se logra articular una marca colectiva eficaz, no faltarán ofertas atrayentes que logren consolidar los esfuerzos de la asociación.

Ciertamente para las sociedades cooperativas, en un mundo cada vez más competitivo y riguroso en las reglas del mercado, la competitividad se ha convertido en un valor consustancial a su naturaleza cooperativa. El mismo progreso «consiste en renovarse», según el criterio de MIGUEL DE UNAMUNO, por lo que la falta de renovación supone la pérdida de aire para la empresa, su pérdida de valor añadido, su muerte económica ante la pérdida de competitividad ${ }^{37}$.

Sobre todo en las pequeñas y medianas empresas ${ }^{38}$, que no pueden permitirse una costosa investigación de mejora de sus líneas de producción o de sus productos, la innovación es vital. Una idea de cualquiera de sus miembros puede ser para ellas motivo de supervivencia o de despegue.

La forma de presentación de un producto, la mejora de un diseño, un toque publicitario que mueva la simpatía de los consumidores, un almacenamiento que facilite la conservación, una relación acorde con el ambiente, cualquier novación aplicada a la empresa, su organización, sus productos, sus servicios, sus relaciones con los clientes o proveedores, puede ser causa de un valor empresarial que facilite el mantenimiento y la vitalidad de la empresa.

En las cooperativas su propia cultura participativa facilita su permanente creatividad, al establecerse en ellas una intervención organizada, incluso como derecho del socio por su propio régimen jurídico. Una de las vías con que cuenta la cooperativa para mantener su posición en el mercado siempre renovada es la marca colectiva.

Sin embargo, es necesario desarrollar un marketing responsable entorno a la marca colectiva pues el concepto que trae aparejado la

37 Nova González, A.: «La reactivación económica del sector agropecuario cubano. Economía y Desarrollo», núm 1, 1995, p. 85

38 CALDERÓN, K.: La marca colectiva, un beneficio para las micro, pequeñas y medianas empresas en Guatemala. Disponible en: www.sieca.org.gt/publico/ProyectosDeCooperacion/proalca/PI/Revistas/R2AB8/LA\%20MarcaLa\%\%20COLECTIVA.htm. Fecha de consulta 13/09/2015. 
misma no se despliega por sí solo, viene acompañado de la conciencia colectiva que demuestre la cooperativa.

Se necesita por lo tanto comenzar a utilizar la marca colectiva como activo intangible de la cooperativa no agropecuaria. Si las nuevas cooperativas, explotan al máximo las funciones que le son inherentes a las marcas, ya estarían construyendo a partir de ahí el valor económico de las mismas.

Esta afirmación se origina teniendo en cuenta que una de las funciones de las marcas persigue ante todo distinguir y diferenciar productos o servicios de otros similares partiendo de su productor, no importa quién sea, lo importante es que siempre sea el mismo. El consumidor confía en que la marca pertenece exclusivamente a una persona, porque aquella no puede tener dos orígenes.

Las relaciones de cooperación y confianza que existen entre los miembros, los estándares de calidad establecidos, la homogeneización de procesos tecnológicos, el conjunto de experiencias y elaboración de estrategias conjuntas entre otros factores, son capaces de proporcionar un origen empresarial más fiel que el transmitido por otras marcas.

FERNÁNDEZ NOVOA ${ }^{39}$ explica que la marca colectiva informa al público acerca de la existencia de un cierto nivel de calidad de los productos o servicios diferenciados por la misma, dicha calidad cristalizará en un goodwill que será compartido por los miembros de la asociación en el tráfico económico.

Justamente con el fin de mantener el correspondiente nivel de calidad, la asociación titular de la marca deberá insertar en el Reglamento de uso las oportunas medidas de control. Estas medidas estarán encaminadas a asegurar una producción homogénea, empleando recursos tecnológicos y materiales iguales; estandarizar la forma de presentación del producto, utilizando los mismos embalajes y diseños; dar a conocer procesos de trazabilidad, informando al consumidor sobre los sucesivos pasos de elaboración, transformación y obtención del producto.

En cuanto a la función condensadora del goodwill, cabe señalar que es la buena fama, reputación o preferencia del público respecto a los productos o servicios diferenciados a través de una marca. En el caso de la marca colectiva dependerá en gran medida del sentido de cooperación de los miembros de la asociación para lograr una clientela fiel a los productos o servicios distinguidos por el signo. Una vez cautivado el público nacional podrán luego rebasarse fronteras a partir del prestigio alcanzado.

39 Fernández NovoA, C.: Tratado..., ob. cit., p. 321. 
La función publicitaria, es aquella que por sí misma realiza la marca, pues ella induce al comprador a seleccionar lo que quiere, constituyendo un medio para crear y perpetuar la buena fama.

"La genuina función publicitaria de la marca colectiva se da cuando esta indica al consumidor que las producciones que diferencia no son fruto del trabajo individual, sino de la colaboración de los miembros de una asociación que han puesto toda su experticia en obtener productos o servicios que tienen como valor agregado el propio hecho de haber sido fruto del esfuerzo colectivo». ${ }^{40}$

Será el reglamento de uso de este signo el que regule cómo desarrollar la publicidad marcaria. Sin embargo, no puede perderse de vista que la cooperativa no agropecuaria como nueva extensión e imagen de la localidad, puede ser dada a conocer junto con su signo distintivo por la propia comunidad que va a sentirse representada por la agrupación.

Si a todo ello se le adiciona una eficaz estrategia de mercado, que logre posicionar a la cooperativa como una de las de mayor preferencia en su tipo por los consumidores, entonces las condiciones del contrato beneficiarán doblemente a esta nueva forma de gestión. Ya no se estará contratando un servicio o una producción "común y corriente», sino una que posee un "valor agregado» y un sello propio que se distingue de cualquier otra de su género. La cooperativa tendrá en sus manos un valioso activo intangible que si sabe explotarse rendirá grandes intereses.

La marca es un bien intangible que no se deprecia con el paso del tiempo, sino que va consolidando su valor económico a través de su permanencia en el comercio. Explotar adecuadamente las funciones de la marca además de ofrecer estabilidad a la misma, permite que la realidad del producto o servicio coincida verdaderamente con la «imagen de marca». Crear inclusive en el caso cubano lo que podría llamarse «imagen cooperativa», sería reafirmar el poder de la marca colectiva, siempre y cuando el producto identificado esté a la altura de lo que exporta dicha imagen.

\section{Aspectos que impiden el registro de la marca colectiva en las cooperativas no agropecuarias cubanas}

Queda claro que la marca colectiva es un signo distintivo con muchas potencialidades, pero con ciertas complejidades, sobre todo, por-

40 Romero Calero, J.: ob. cit. p. 67. 
que su vida gira alrededor de la asociación titular del mismo. En tal sentido, los aspectos que impiden su desarrollo están ligados precisamente a este elemento esencial de la marca colectiva.

Aunque en Cuba hay una fuerte vocación solidaria que pudiera favorecer el proceso de creación de una cooperativa y con ella el de una marca colectiva, hay que tener en cuenta, la lógica complejidad de los procesos asociativos, por lo que en muchas ocasiones no se llegan a constituir reales asociaciones cooperativas donde la cooperación sea asumida por sus miembros como una responsabilidad y no como un acto de espontaneidad derivado de la idiosincrasia del cubano.

En Cuba el sector no agropecuario carece de una cultura cooperativista a partir de los principios que rigen el cooperativismo. No siempre se logra que las cooperativas que se están constituyendo sean conformadas por miembros que tenían ciertas relaciones de afinidad y empatía, por lo que será un error forzar la solicitud de una marca colectiva en estos casos, hasta tanto no se logre una real integración entre sus miembros y haya un real conocimiento de los elementos esenciales y potencialidades de las marcas colectivas, aunque en este sentido estamos trabajando.

\section{A modo de conclusiones}

El nuevo cooperativismo cubano ofrece a la sociedad un modelo de gestión diferente, en la que la motivación y el compromiso institucional son soportes de la eficacia y de la eficiencia de la organización, la cual se construye como una auténtica alternativa de desarrollo socioeconómico, donde el ser humano es eje fundamental de todo el accionar.

La gestión cooperativa está integrada también por una gestión de marca, o sea, por ese conjunto de acciones que se desarrollan para el efectivo desenvolvimiento del signo distintivo y que tributan en favor de la asociación y sus miembros. Por lo tanto, una adecuada gestión de marca contribuirá al perfeccionamiento de la gestión cooperativa.

En este sentido, la gestión de marca colectiva debe consolidar la identidad cooperativa promocionando los valores y principios cooperativos en los que se sustenta. Debe promover estrategias de comunicación usando nuevas tecnologías que logren la apropiación del modelo cooperativo por parte de los asociados; trabajar por el mejoramiento continuo de la oferta de productos y servicios que el movimiento cooperativo aporta al mercado; productos y servicios de calidad superior que generen mayores niveles de confianza y credibilidad. 
La marca colectiva institucionaliza en la cooperativa, a través de su reglamento de uso, las dimensiones: tecnológica, socio-ambiental y comercial que son básicas para su competitividad.

Solamente es necesario un mercado competitivo y la gestión de marca se hace imprescindible. En el mundo actual en el cual los productos y servicios difieren cada vez menos unos de otros, sólo el ofrecer una imagen auténtica y demostrar la calidad bastarán para tener una oportunidad de éxito.

La marca colectiva y el cooperativismo se articulan bajo una relación de complementariedad recíproca, pues si bien la asociación es la base para la solicitud y desarrollo de una marca colectiva, esta a través de su reglamento de uso fortalece los principios que rigen el cooperativismo, al internalizar normas que favorecen la gestión colectiva como condición para la sostenibilidad de este modelo de gestión empresarial.

\section{Bibliografía}

\section{Textos básicos}

BERCOVITZ, A.: Nociones introductorias sobre las marcas, España, 1989, Disponible en: books.google.com.cu/books.

Borjabad Gonzalo, P.: Manual de Derecho Cooperativo. General y Catalán, Bosch, Barcelona, 1993, ISBN: 84-7698-263-1.

Candano Perez, M.: «El Derecho marcario y la influencia de la marca colectiva en el turismo cubano», Retos turísticos, núm 3, vol 11, 2012, ISSN: 16819713.

CheValer, M.: Prólogo por qué las marcas son buenas para usted, Michel Chevalier, Gerald Mazzalovo, Belacqva, Barcelona, 2005.

Divar Garteizaurrecoa, J.: "El Derecho comparado cooperativo en Europa», Anuario de estudios cooperativos, 1988, pp. 111 y ss.

Fernández NovoA, C.: La Marca Comunitaria. España. 1990.

TRATAdo Sobre Derecho de Marcas, Marcial Pons, Ediciones Jurídicas y Sociales, S.A, Madrid, 2001.

García-Gutiérrez Fernández, C.: «Las personas jurídicas como socios de las sociedades cooperativas de primer grado o cooperativas propiamente dichas: necesidad de una revisión legal», REVESCO, núm 60, 1994, pp. 61y ss.

GARCíA JiMÉNEZ, M.: «La necesaria armonización internacional del Derecho Cooperativo», REVESCO, Segundo Cuatrimestre, núm 102, p. 79 y ss.

García Muñoz-NAJAR, LA.: Marcas Colectivas, Marcas de Certificación y denominaciones de origen. Acerca de las normas de calidad y uso de los signos distintivos para competir en el mercado, INDECOPI, Perú, 2012.

GiRón TenA, J.: Derecho de sociedades. En: AA.VV. Tomo I: parte general, Sociedades Colectivas y Comanditarias, Editorial G.T, Madrid, 1976. 
González Gutiérrez, A.: «Economía y sociedad: los retos del modelo económico», Cuba: Investigación Económica, núm 3-4, 2007, pp.1 y ss.

LEON LUNA, D.: La marca colectiva en el sector cooperativo, Tesis en opción al grado de licenciado en Derecho, Universidad de Matanzas, 2015.

MilLS, C. y DAVIES., W.: «Plan para una década cooperativa», Revista Alianza Cooperativa Internacional, núm 1, 2013.

Oficina Cubana de la Propiedad Industrial. Manual de Marcas para el Empresariado Cubano/ OCPI. Departamento de Marcas, La Habana, 2014.

Paz Canalejo, N.: «La Asamblea General en la Ley 27/1999 de Cooperativas: reflexiones crítica», REVESCO, núm 78, 2002, p. 121y ss.

Rodríguez Calvo, H.: «Las marcas: clave estratégica para las PYMES en América Latina», Rendija, núm 5, 2005.

Romero Calero, J.: La marca colectiva en la gestión empresarial cubana. Tesis para optar por el grado científico de Máster en Gestión de la Propiedad Intelectual, La Habana, Cuba, 2009, p. 38.

Sánchez Calero.: Instituciones de Derecho Mercantil, Editoriales de Derecho Reunidas, España, 1994.

VARGAS VASSEROT, C.: La actividad cooperativizada y las relaciones de la cooperativa con sus socios y con terceros. Navarra: Aranzadi, 2006, pp. 248 y ss, ISBN: 84-8355-007-6.

\section{Legislación}

Decreto-Ley 305 «De las Cooperativas no Agropecuarias», de fecha 11 de diciembre de 2012. Publicado en la Gaceta Oficial Extraordinaria No. 53, del 11 de diciembre de 2012, disponible en: http//www.gacetaoficial.cu

Decreto 309 «Reglamento de las cooperativas no agropecuarias de primer grado, de fecha 28 de noviembre de 2012.

Decreto-Ley 203/99 «De marcas y otros signos distintivos», edición extraordinaria No.3 del 2 de mayo de 2000.

Ley No. 95, "Ley de Cooperativas de Producción Agropecuaria y de Créditos y Servicios» Publicada en la Gaceta Oficial de la República de Cuba No.72, con fecha 29 de noviembre de 2002. 